\title{
Bone mesenchymal stem cells differentiate into myofibroblasts in the tumor microenvironment
}

\author{
JING ZHANG $^{1 *}$, DINGQI SUN ${ }^{2 *}$, QIANG FU $^{2}$, QINGWEI CAO ${ }^{2}$, HUI ZHANG $^{2}$ and KEQIN ZHANG ${ }^{2}$ \\ Departments of ${ }^{1}$ Nephrology and ${ }^{2}$ Urology, Shandong Provincial Hospital Affiliated to Shandong University, \\ Jinan, Shandong 250021, P.R. China
}

Received February 11, 2015; Accepted February 19, 2016

DOI: $10.3892 / \mathrm{ol} .2016 .4645$

\begin{abstract}
The aim of the present study was to investigate the tropism of mesenchymal stem cells (MSCs) to the tumor microenvironment, and to evaluate the feasibility of bone marrow mesenchymal stem cells differentiating into myofibroblasts in vitro. A total of $1 \mathrm{ml}$ bone marrow was extracted from the greater trochanter of one male New Zealand rabbit, and MSCs were obtained by density gradient centrifugation and cultured routinely. The surface markers were analyzed by flow cytometry. A VX2 tumor was aseptically excised from another male New Zealand rabbit and primary cultured. The tropism of MSCs for $30 \%$ and $50 \%$ VX2 conditioned medium was determined by using Transwell migration assays. MSCs were incubated in $30 \% \mathrm{VX} 2$ conditioned medium for 7 or 14 days. The messenger (m)RNA levels and protein expression of $\alpha$-smooth muscle actin ( $\alpha$-SMA) and vimentin were measured by reverse transcription-polymerase chain reaction and western blotting. MSCs were observed to have a spindle shape. The cultured MSCs were cluster of differentiation (CD) $44^{+}, \mathrm{CD} 105^{+}, \mathrm{CD} 106^{+}$ and CD34- VX2 cells demonstrated a spindle or polygon shape. In the Transwell assay, it was observed that the migrated cells appeared more frequently in the $30 \%$ VX 2 conditioned medium group compared with the other groups when microscopically examined, which was additionally confirmed by the results of a colorimetric assay. The mRNA levels and protein expression of $\alpha$-SMA and vimentin significantly increased in the test group compared with the control group at 7 days $(\mathrm{P}<0.01)$, and further increased in the test group at 14 days $(\mathrm{P}<0.01)$. The results of
\end{abstract}

Correspondence to: Dr Keqin Zhang, Department of Urology, Shandong Provincial Hospital Affiliated to Shandong University, 324 Jingwuweiqi Road, Jinan, Shandong 250021, P.R. China

E-mail: kqzhang81@aliyun.com

*Contributed equally

Abbreviations: MSCs, mesenchymal stem cells; GAPDH, glyceraldehyde-3-phosphate dehydrogenase

Key words: bone marrow mesenchymal stem cells, differentiation, tumor microenvironment, myofibroblast the present study demonstrated that MSCs have tropism for the tumor microenvironment and furthermore, may differentiate into myofibroblasts in the tumor microenvironment in vitro. The present study suggested that MSCs may migrate to the tumor and subsequently differentiate into myofibroblasts due to the tumor microenvironment, which may lead to promotion of the growth of the tumor. The present study additionally suggested that MSCs may be the precursors of tumor/carcinoma-associated myofibroblasts.

\section{Introduction}

Stromal cells are the most important components of carcinoma and have a significant role in cancer development (1). Myofibroblasts constitute the bulk of the cancer stroma; these cells are activated, non-transformed fibroblasts that express $\alpha$-smooth muscle actin ( $\alpha$-SMA) (2) and are observable in various human carcinomas (3). Myofibroblasts are able to promote cancer initiation, angiogenesis, invasion and metastasis (4) by secretion of elevated levels of growth factors, chemokines and matrix metalloproteinases (MMPS) $(5,6)$. The origin of myofibroblasts in tumors remains to be fully elucidated. Fibrocytes (7), pericytes (8) and smooth muscle cells (9) are thought to be the precursors of myofibroblasts. However, certain studies have demonstrated that bone mesenchymal stem cells (MSCs) may be the source of myofibroblasts (10-12).

MSCs are defined by their self-renewal, plastic adherence and multiple differentiation potential (13). MSCs possess the capacity to differentiate into osteoblasts, adipocytes, chondrocytes, myocytes and cardiomyocytes depending on the defining microenvironment (14). Previous studies have reported that engrafted MSCs are able to differentiate into myofibroblasts (15) and promote tumor growth in a rabbit bladder cancer model (16). MSCs additionally exhibit tropism, which means that they are attracted to sites of tissue injury, as well as tumor microenvironments. The tropism of MSCs may be controlled by inflammatory mediators produced during tissue damage or by the tumor microenvironment $(17,18)$.

The VX2 tumor is derived from Shope papilloma virus, which induces malignant papilloma formation of a malignant epithelial tumor that is a type of squamous cell carcinoma (19). In a previous study by the present authors, it was observed that MSCs were able to differentiate into myofibroblasts in a rabbit VX2 bladder cancer model (15). In the present study, 
a primary culture of MSCs and VX2 cells was utilized to demonstrate the tropism of MSCs, as well as their capacity to differentiate into myofibroblasts in VX2 conditioned medium. The results of the present study provide evidence that MSCs may be the precursor of myofibroblasts.

\section{Materials and methods}

Animals. A total of 6 three-month old male New Zealand rabbits, weighing $\sim 1.5 \mathrm{~kg}$, were purchased from the Shandong Academy of Agricultural Sciences (Jinan, China). One three-month old male New Zealand rabbit, weighing $2 \mathrm{~kg}$, with a VX2 tumor was obtained from Shanghai Jiao Tong University School of Medicine (Shanghai, China). The rabbits were maintained in specific pathogen-free environment at a temperature of $23 \pm 1^{\circ} \mathrm{C}$ with a $12 \mathrm{~h}$ light/dark cycle and supplied rabbit chow and water ad libitum. The present study was approved by the Ethics Committee of the Shandong Provincial Hospital Affiliated to Shandong University (Jinan, China; approval no., 2014-003).

MSC isolation and culture. Rabbit MSCs were aspirated from the bone marrow of the proximal tibia of one male rabbit. MSCs were isolated as described previously (10) through the gradient centrifugation method as follows: The aspirates were mixed with an equal volume of phosphate-buffered saline (PBS) and centrifuged (Heraeus ${ }^{\mathrm{TM}} \mathrm{Pico}^{\mathrm{TM}}$ microcentrifuge; Thermo Fisher Scientific, Inc., Waltham, MA, USA) at room temperature (1,200 x $\mathrm{g}$ for $5 \mathrm{~min})$; the pellets were suspended in $5 \mathrm{ml}$ PBS and were added to $4 \mathrm{ml}$ lymphocyte separating medium (Tianjin Haoyang Biological Products Technology Co., Ltd., Tianjin, China) and centrifuged again $(2,000 \mathrm{x}$ g for $20 \mathrm{~min})$; the stratum intermedium was suspended in $6 \mathrm{ml}$ PBS and centrifuged $(1,200 \times \mathrm{g}$ for $5 \mathrm{~min})$ and the pellets were suspended in $6 \mathrm{ml}$ PBS and centrifuged at $1,000 \mathrm{x} \mathrm{g}$ for $5 \mathrm{~min}$. Subsequently, the MSC pellets were suspended in low-glucose Dulbecco's modified Eagle's medium (DMEM; Gibco; Thermo Fisher Scientific, Inc.) supplemented with $10 \%$ calf-serum (Gibco; Thermo Fisher Scientific, Inc.) and $100 \mathrm{U} / \mathrm{ml}$ penicillin-streptomycin mixture (Shanghai Solarbio Science \& Technology Co., Ltd., Shanghai, China), followed by plating at an initial seeding density of $4.0 \times 10^{5} / \mathrm{cm}^{2}$. Nonadherent cells were removed following $72 \mathrm{~h}$ of incubation and the culture medium was replaced every 3 days. When cells grew to $80 \%$ confluence, they were trypsinized $(0.25 \%$ trypsin; Sigma-Aldrich, St. Louis, MO, USA) and subcultured in a 1:2 split. Flow cytometry (FC500 Flow Cytometer; Beckman Coulter, Inc., Brea, CA, USA) was performed in order to identify passage 2 MSCs using mouse anti-rabbit cluster of differentiation (CD) 34 (cat. no. MCA547B; dilution, 1:15), anti-CD44 (cat. no. MCA806GA; dilution, 1:15), anti-CD105 (cat. no. MCA1557; dilution, 1:15) and anti-CD109 (cat. no. MCA907F; dilution, 1:15) primary antibodies (AbD Serotec, Kidlington, UK) $\left(4^{\circ} \mathrm{C}\right.$ incubation for $\left.30 \mathrm{~min}\right)$ and sheep anti-mouse fluorescein isothiocyanate labeled secondary antibody (cat. no. ZDR-5307; dilution, 1:15; Beijing Zhongshan Jinqiao Biotechnology Co., Ltd., Beijing, China) (room temperature incubation for $1 \mathrm{~h}$ ). The experiment was repeated three times.

VX2 cell isolation and culture. As previously described (10), an aseptically excised tumor ( $>3 \mathrm{~cm}$ volume), which had been grown
Table I. Rabbit-specific primer sequences.

\begin{tabular}{llc}
\hline Primer & \multicolumn{1}{c}{ Sequence } & Size, bp \\
\hline$\alpha$-SMA & GTGTGAGGAAGAGGACAGCA & 391 \\
& TACGTCCAGAGGCATAGAGG & \\
Vimentin & CTTCTCAGCATCACGACC & 146 \\
& ATCTATCTTGCGCTCCTG & \\
GAPDH & GAGCTGAACGGGAAACTCAC & 476 \\
& GGTCTGGGATGGAAACTGTG & \\
&
\end{tabular}

SMA, smooth muscle actin; GAPDH, glyceraldehyde-3-phosphate dehydrogenase.

in a male New Zealand rabbit for 4 weeks, was cut with scissors into sections $(<1 \mathrm{~mm}$ in diameter) following euthanization with $100 \mathrm{mg} / \mathrm{kg}$ sodium pentobarbital (New Asia Pharmaceutical Co., Ltd., Shanghai, China). The sections were trypsinized in $0.25 \%$ trypsin and $0.1 \%$ collagenase I (Gibco; Thermo Fisher Scientific, Inc.) at $37^{\circ} \mathrm{C}$ for $20 \mathrm{~min}$. The mixture was filtered using a $200 \mu \mathrm{m}$ nylon mesh filter and the cells were suspended in RPMI-1640 medium (Gibco; Thermo Fisher Scientific, Inc.) supplemented with $15 \%$ calf-serum and $100 \mathrm{U} / \mathrm{ml}$ penicillin-streptomycin mixture, followed by plating at an initial seeding density of $4.0 \times 10^{5} / \mathrm{cm}^{2}$. Nonadherent cells were removed following $72 \mathrm{~h}$ of incubation and the culture medium was replaced every 2 days. When cells grew to $80 \%$ confluence, they were trypsinized ( $0.25 \%$ trypsin). The cells were then fixed in $4 \%$ paraformaldehyde (Macklin Biochemical Co., Ltd., Shanghai, China) at the room temperature for $30 \mathrm{~min}$., stained with hematoxylin and eosin (Chengdu Rich Science Industry Co., Ltd., Chengdu, China) and the morphology of cells was analyzed using a microscope (CX23; Olympus Corporation, Tokyo, Japan).

In vitro migration assay. The tropism of MSCs for VX2 cells was determined using an in vitro migration assay. MSCs in serum-free low-glucose DMEM were placed into the upper well of $24 \mathrm{~mm}$ tissue culture Transwell plates $(12 \mu \mathrm{m}$; EMD Millipore, Billerica, MA, USA) coated with Matrigel [90 $\mu 1$ endothelial cell medium (Matrigel; Sigma-Aldrich) diluted in $270 \mu \mathrm{l}$ low-glucose DMEM]. VX2 cells were incubated at $37^{\circ} \mathrm{C}$ in RPMI-1640 medium supplemented with $15 \%$ calf-serum for $48 \mathrm{~h}$. The resulting conditioned medium was aspirated and prepared for the subsequent experiments. The cells were divided into three groups as follows, based on the medium placed into the lower well of the Transwell plates: Control group (low-glucose DMEM supplemented with 10\% calf-serum), Test 1 group (low-glucose DMEM supplemented with $10 \%$ calf-serum and $30 \%$ VX2 conditioned medium) and Test 2 group (low-glucose DMEM supplemented with $10 \%$ calf-serum and 50\% VX2 conditioned medium). MSCs were incubated for $12 \mathrm{~h}$ at $37^{\circ} \mathrm{C}$. The migrated cells were stained using crystal violet (A. B. Enterprises, Mumbai, India) and observed under a microscope (CX23; Olympus Corporation). The migration ratio was determined by using a colorimetric assay (WSL-2 colorimeter; Shanghai Laipade Science Instruments Co., Ltd., Shanghai, China). All experiments were performed in triplicate. 
A

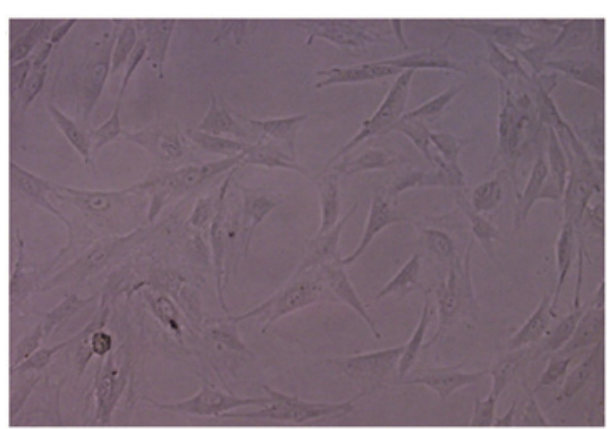

B

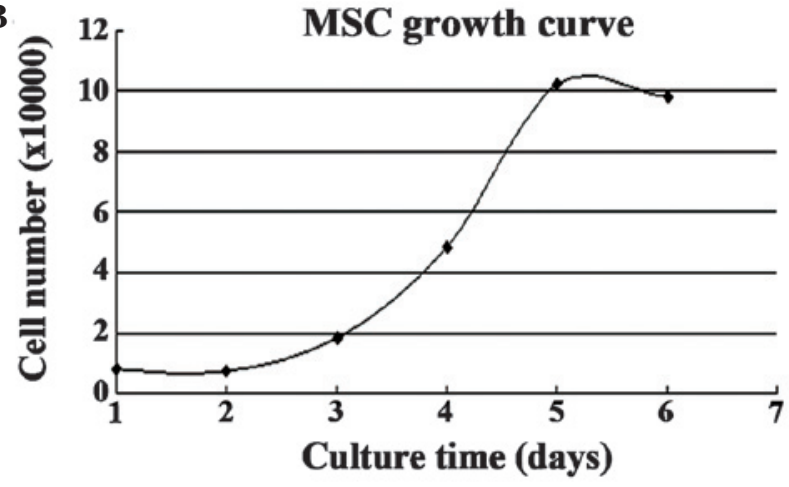

C
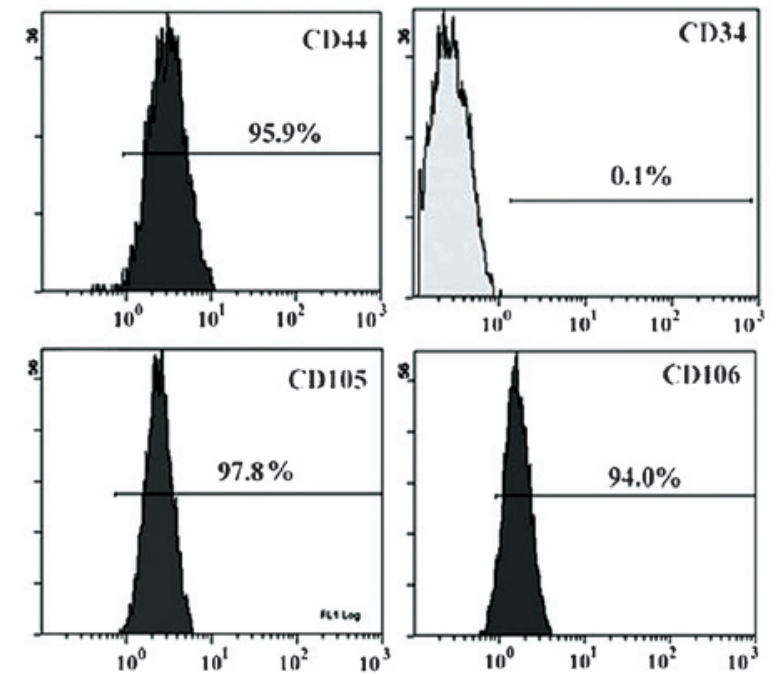

Figure 1. Characterization of MSCs. (A) Spindle-shaped MSCs (no staining; magnification, x200). (B) MSC growth curve forms an 'S' shape. (C) Representative data from flow cytometry. The majority of MSCs were positive for CD44, CD105 and CD106, but negative for CD34. MSC, mesenchymal stem cell; CD, cluster of differentiation.

Reverse transcription-polymerase chain reaction $(R T-P C R)$. MSCs were incubated in conditioned medium (low-glucose DMEM supplemented with $10 \%$ calf-serum and $30 \%$ VX2 conditioned medium) for 7 or 14 days at $37^{\circ} \mathrm{C}$. Total RNA was extracted from the MSCs and purified with the RNeasy Mini kit (Qiagen China Co., Ltd., Shanghai, China), according to the manufacturer's protocol. RT of the total RNA was performed using the PrimeScript ${ }^{\mathrm{TM}}$ 1st Strand cDNA synthesis kit (Takara Biotechnology Co., Ltd., Dalian, China). Glyceraldehyde-3-phosphate dehydrogenase (GAPDH) was utilized as the loading control gene, whereby each RT sample was normalized to the GAPDH level. The PCR was performed with rabbit primers (Table I; Invitrogen; Thermo Fisher Scientific, Inc.). The PCR was performed in a thermal cycler (Gene Cycler ${ }^{\mathrm{TM}}$, Bio-Rad Laboratories, Inc., Hercules, CA, USA). The cycling conditions were as follows: 22 cycles at $94^{\circ} \mathrm{C}$ for $1 \mathrm{~min}, 58^{\circ} \mathrm{C}$ for $60 \mathrm{sec}, 72^{\circ} \mathrm{C}$ for $60 \mathrm{sec}$ and $72^{\circ} \mathrm{C}$ for $7 \mathrm{~min}$. PCR products were electrophoresed on a $1 \%$ agarose gel containing ethidium bromide (Beijing NuoqiYa Biotechnology Co., Ltd., Beijing, China), and were visualized and images were captured using an ultraviolet transilluminator (UVsolo TS; Biometra GmbH, Göttingen, Germany). The experiment was performed in triplicate and diethyl pyrocarbonate water was used as the negative control.

Western blotting. As mentioned previously, MSCs were incubated in conditioned medium (low-glucose DMEM supplemented with $10 \%$ calf-serum and $30 \%$ VX2 conditioned medium) for 7 or 14 days at $37^{\circ} \mathrm{C}$. To identify the protein expression of $\alpha$-SMA and vimentin, western blotting was performed. Protein extracts were separated using 14\% sodium dodecyl sulfate polyacrylamide gel electrophoresis and transferred to polyvinylidene difluoride membranes. Following blocking with 5\% non-fat dry milk for $1 \mathrm{~h}$ at room temperature, the membrane was incubated overnight at $4^{\circ} \mathrm{C}$ with the appropriate primary antibody (monoclonal mouse anti-rabbit $\alpha$-SMA; cat. no. 04-1100; dilution, 1:1,000, EMD Millipore; or polyclonal mouse anti-rabbit vimentin; cat. no. ab45939; dilution, 1:200; Abcam, Cambridge, UK). Subsequently, the membrane was washed three times with Tris-Buffered Saline and Tween 20 for $30 \mathrm{~min}$, followed by incubation with secondary antibody (horseradish peroxidase-conjugated polyclonal sheep anti-mouse antibody; cat. no. ZDR-5307; dilution, 1:5,000; Beijing Zhongshan Jinqiao Biological Technology Co., Ltd., Beijing, China) for $1 \mathrm{~h}$ at room temperature. The labeled proteins were visualized using ECL Western Blotting Detection System (BestBio Company, Shanghai, China) and exposed to film. Polyclonal goat anti-rabbit $\beta$-actin (cat. no. TA-09; dilution, 1:500; Beijing Zhongshan Jinqiao Biological Technology Co., Ltd.) was used as a protein loading control.

Statistical analysis. All data are expressed as the mean \pm standard deviation. Differences between two groups were compared 

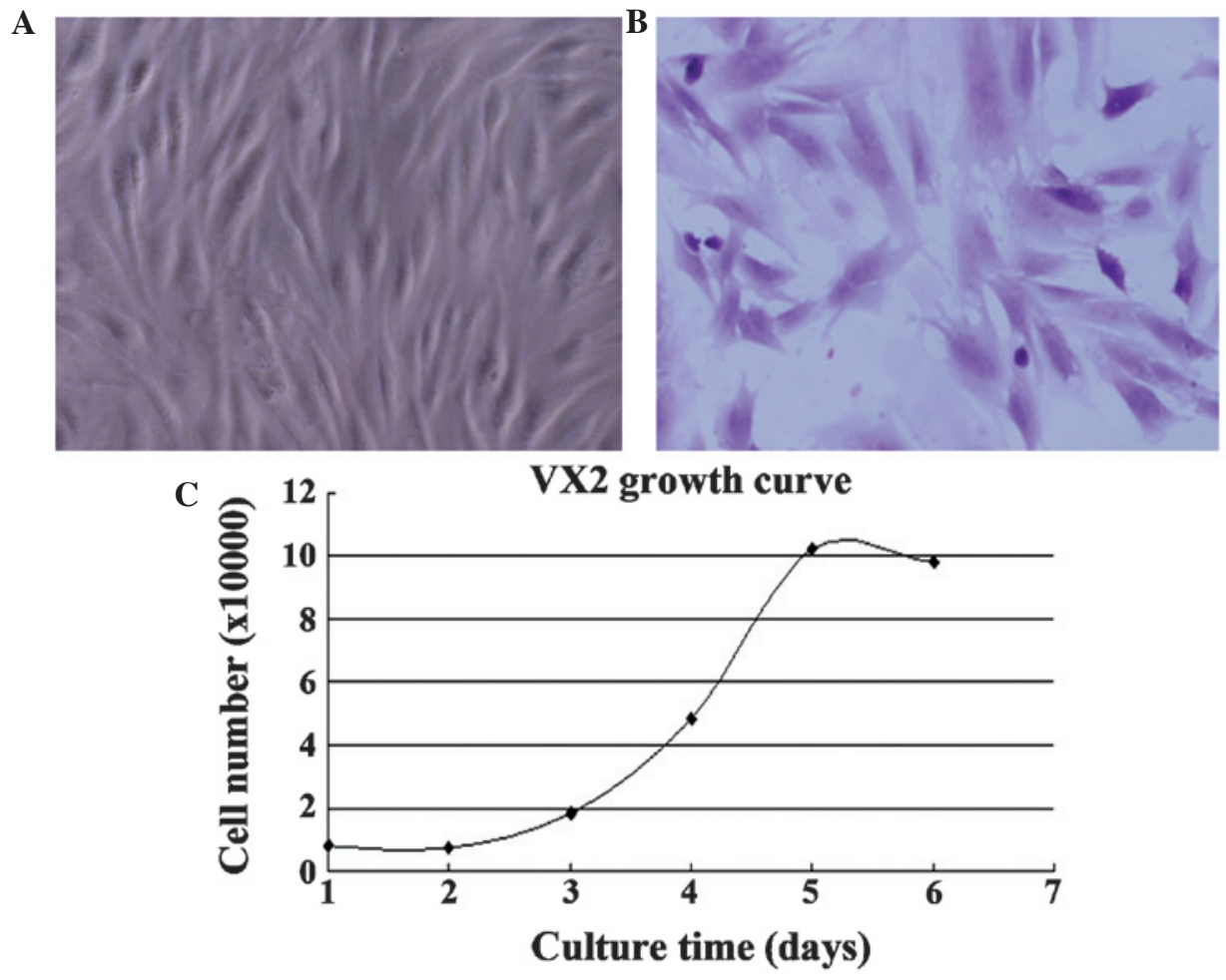

Figure 2. Characterization of VX2 cells. (A) VX2 cells exhibited a spindle or polygon shape (no staining; magnification, x200). (B) Hematoxylin and eosin-stained VX2 cells (magnification, x200). (C) VX2 cell growth curve.

A

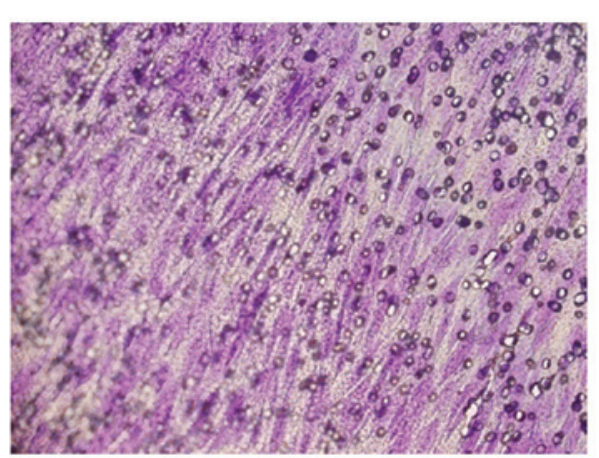

C

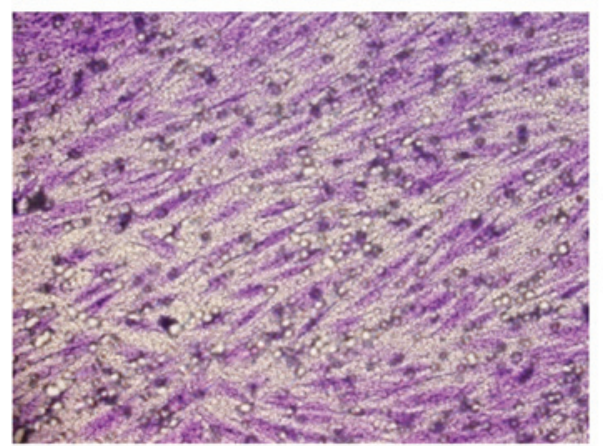

B
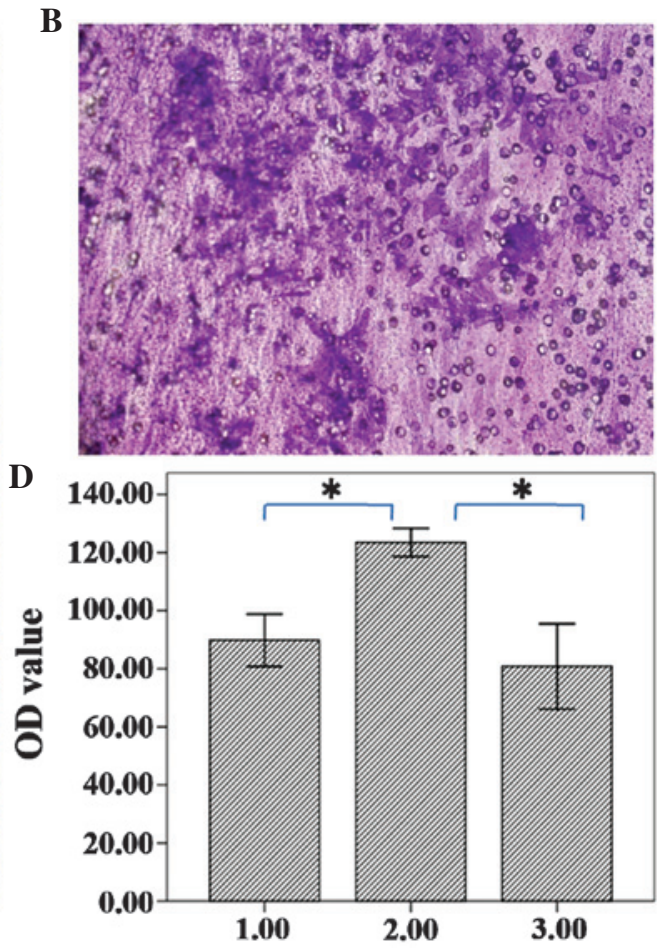

Figure 3. Tropism of MSCs for VX2 cells. (A) Control group; (B) Test 1 group (30\% VX2 conditioned medium); (C) Test 2 group (50\% VX2 conditioned medium) (crystal violet staining; magnification, x200). (D) The OD value of migrated cells in the control (1.00), Test $1(2.00)$ and Test $2(3.00)$ groups; ${ }^{*} \mathrm{P}<0.05$. Data are presented as the mean \pm standard deviation. MSC, mesenchymal stem cell; OD, optical density.

using the Student's t-test and differences between multiple groups were analyzed by one-way analysis of variance, using SPSS version 17.0 (SPSS, Inc., Chicago, IL, USA). P<0.05 was considered to indicated a statistically significant difference.

\section{Results}

MSCs and VX2 cell isolation and culture. MSCs possessed a spindle shape (Fig. 1A) and their doubling time at passage 2 


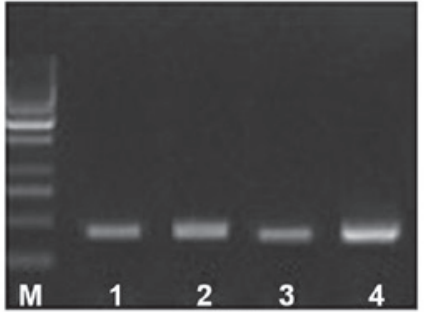

a-SMA

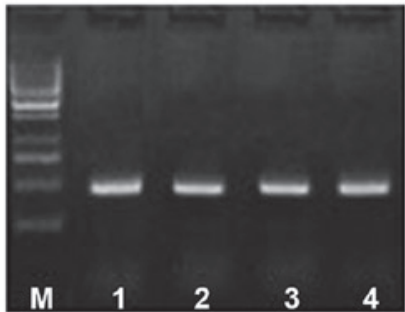

GAPDH

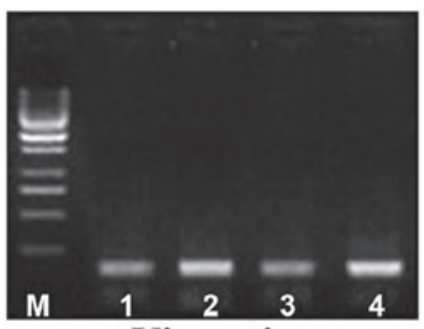

Vimentin
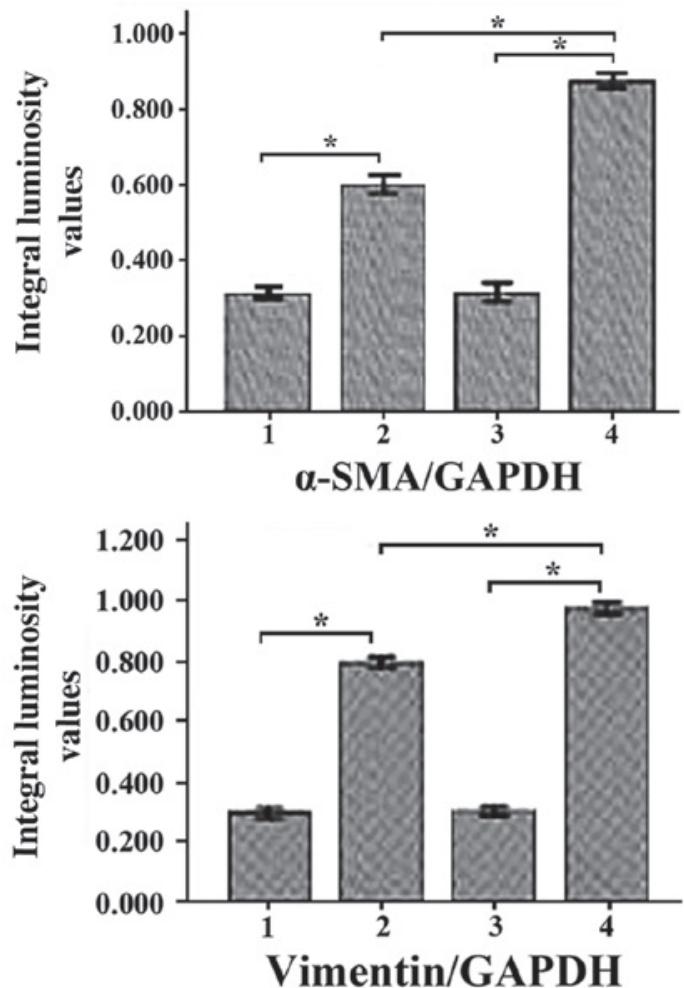

Figure 4. Messenger RNA levels of $\alpha$-SMA, vimentin and GAPDH. Mesenchymal stem cells were incubated in various groups in conditioned medium for 7 or 14 days as follows: 1,7 days control group; 2,7 days test group; 3,14 days control group; 4,14 days test group. ${ }^{*} \mathrm{P}<0.05$. Data are presented as the mean \pm standard deviation. SMA, smooth muscle actin; GAPDH, glyceraldehyde-3-phosphate dehydrogenase; M, marker.
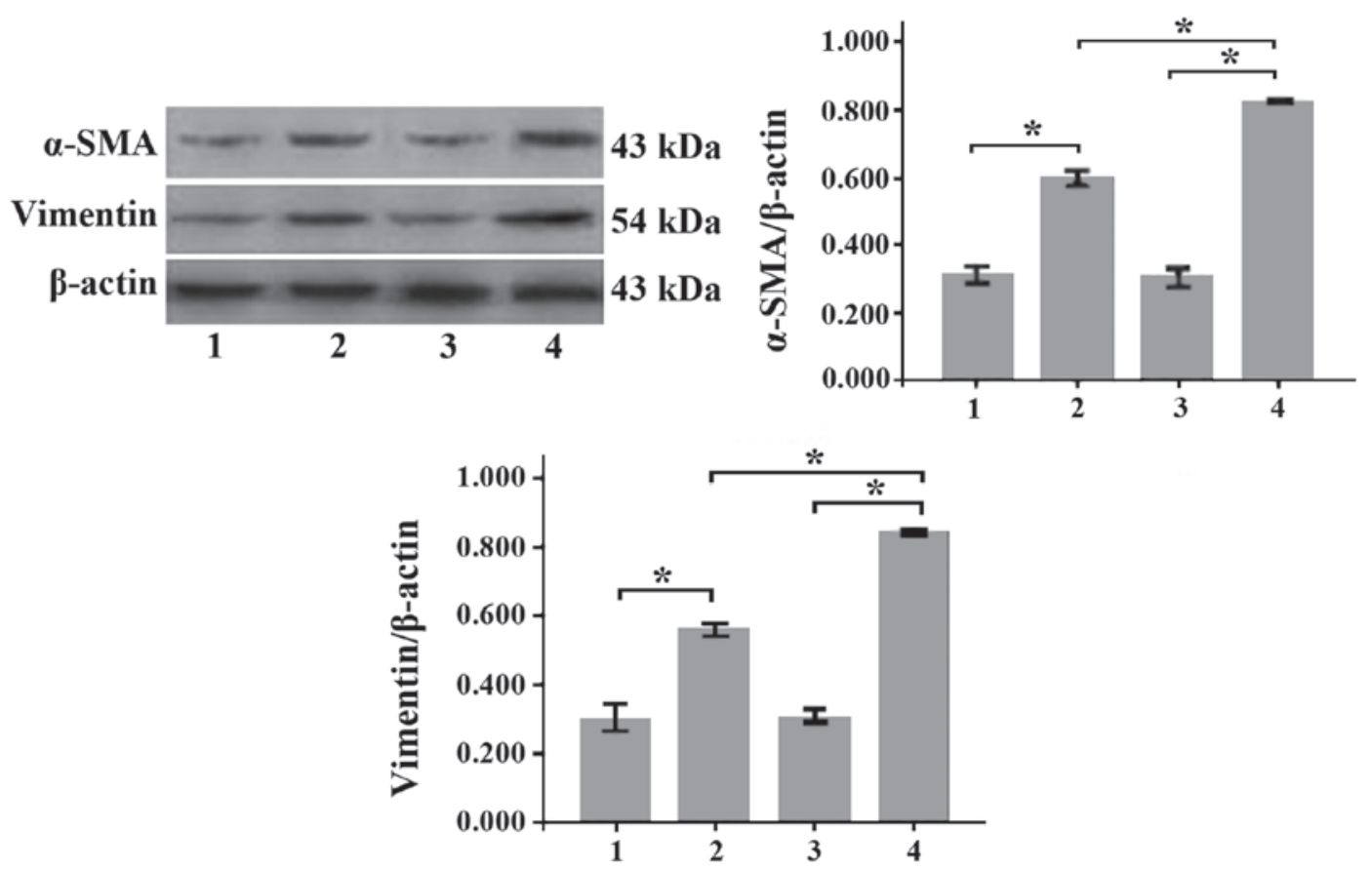

Figure 5. The protein expression of $\alpha$-SMA and vimentin. Mesenchymal stem cells were incubated in various groups in conditioned medium for 7 or 14 days as follows: 1,7 days control group; 2,7 days test group; 3,14 days control group; 4,14 days test group. " $\mathrm{P}<0.05$. Data are presented as the mean \pm standard deviation. SMA, smooth muscle actin.

was $\sim 30 \mathrm{~h}$ (Fig. 1B). MSCs were positive for CD44, CD105 and CD106, but negative for CD34 expression (Fig. 1C). VX2 cells exhibited a spindle or polygon shape (Fig. 2A and B). Their doubling time at passage 2 was $\sim 22 \mathrm{~h}$ (Fig. 2C).
Tropism of MSCs to the tumor microenvironment. The majority of the MSCs migrated through the Matrigel in all three groups, and the migrated cells demonstrated an uneven distribution. The cells of Test 1 group had increased migration compared 
with the other groups under microscope (magnification, $\mathrm{x} 200$; CX53; Olympus Corpoation), which was additionally confirmed by the results of the colorimetric assay. The results for the control group, Test 1 group and Test 2 groups were $0.0898 \pm 0.0110,0.1235 \pm 0.0059$ and $0.0808 \pm 0.0179$, respectively, which indicated that Test 1 group cells had migrated significantly more compared with the other groups (Fig. 3). These results suggested that $30 \%$ VX2 conditioned medium may induce increased myofibroblast generation compared with $50 \%$ VX2 conditioned medium, which may mean that $30 \%$ VX2 conditioned medium is the most suitable concentration for tropism of myofibroblast cells.

MSCs differentiate into myofibroblasts. Following incubation of MSCs with conditioned medium for 7 and 14 days, it was subsequently observed that the mRNA levels of $\alpha$-SMA and vimentin (myofibroblast markers) (11) had significantly increased in a time-dependent manner $(\mathrm{P}<0.01$; Fig. 4$)$. The protein levels of $\alpha$-SMA and vimentin were additionally observed to have increased significantly in a time-dependent manner $(\mathrm{P}<0.01$; Fig. 5).

\section{Discussion}

Myofibroblasts were first identified in granulation tissue by Gabbiani and Majno (20) in 1972, and have been subsequently observed in a wide range of normal and abnormal tissues $(21,22)$. Prior to the study by Gabbiani and Majno, there had not been an exact definition of myofibroblasts, as their appearance and function was not invariable within different tissues. Currently, it is generally accepted that myofibroblasts possess similar features to fibroblasts and smooth muscle cells, as they express the fibroblast marker vimentin and the smooth muscle marker $\alpha$-SMA (23). Myofibroblasts have roles in contraction, secretion and synthesis, and possess a significant role in injury healing, organogenesis and tissue molding (24,25).

Myofibroblasts are an important component of tumors/carcinomas; these cells are known as tumor/carcinoma-associated myofibroblasts and differ from the myofibroblasts observed within normal tissues (26). Tumor/carcinoma-associated myofibroblasts are perpetually activated, and do not undergo apoptosis or elimination, which results in tumor/carcinoma growth and development (27). It has been reported that myofibroblasts promote tumor/carcinoma growth and progression by secretion of growth factors, chemokines and MMPs (28). In prostate cancer, myofibroblasts promote cancer cell growth and invasion by increasing the expression of chemokine $(\mathrm{C}-\mathrm{X}-\mathrm{C}$ motif) ligand (CXCL)12, CXCL14, MMP2 and MMP3 (29). It has been reported that myofibroblasts may promote cancer cell growth, angiogenesis and invasion by increasing the expression of CXCL12, MMP9 and MMP14 in breast cancer (30). Due to the accumulating evidence of their cancer-promoting effects, myofibroblasts may be promising novel therapeutic targets for the treatment of cancer (31).

The source of tumor/carcinoma-associated myofibroblasts remains to be elucidated. Certain previous studies reported that tumor/carcinoma-associated myofibroblasts may be derived from myofibroblasts within normal tissue, which are activated by transforming growth factor (TGF) $\beta 1$ and basic fibroblast growth factor $(32,33)$. Another study reported that bone marrow was the primary source of tumor/carcinoma-associated myofibroblasts (34), and an alternative study proposed that epithelial to mesenchymal transition may be responsible for the origin of myofibroblasts (35). The present study demonstrated that myofibroblasts may be derived from bone marrow MSCs. The following characteristics of MSCs suggest that they may be the precursors of myofibroblasts: Multiple differentiation potential and tropism (36). The results of the present study revealed that MSCs were able to differentiate into myofibroblasts in the presence of conditioned medium, which suggested that MSCs may be the primary source of myofibroblasts. The mechanism underlying this process remains to be elucidated. It was inferred that chemokines/cytokines secreted by tumor/cancer cells had a significant role. Tumor/cancer cells produce epidermal growth factor, platelet-derived growth factor, vascular endothelial growth factor and TGF $\beta 1$, and TGF $\beta 1$ in particular promotes the transdifferention process (37). A previous study observed that tumor/cancer-derived lysophosphatidic acid was involved in the differentiation of MSCs to myofibroblasts (38).

In the present study, the cells of Test 1 group had increased migration compared with the control group, which demonstrated the tropism of MSCs to the tumor microenvironment, which was consistent with previous studies $(39,40)$. Furthermore, it is notable that migrated cells were significantly increased in the $30 \% \mathrm{VX} 2$ conditioned medium group compared with the $50 \%$ VX2 conditioned medium group, however, these results contradict the results of previous studies $(39,40)$. There may be various reasons for this result. Culturing MSCs is challenging and minor alterations in the composition of media may cause cell death. The composition of VX2 conditioned medium was complex and included a wide range of chemokines/cytokines and metabolic products. The results of the migration assay suggested that $30 \% \mathrm{VX} 2$ conditioned medium may be more appropriate, rather than $50 \%$ VX2 conditioned medium. There were a number of limitations of the present study. A component analysis of the VX2 conditioned medium was not performed to additionally investigate the mechanism of MSC differentiation into myofibroblasts. These underlying mechanisms are of great interest for future studies.

In conclusion, MSC differentiation into myofibroblasts observed in the tumor/cancer stroma may be mediated by a range of chemokines/cytokines produced by the tumor/cancer, and this may be the primary source of tumor/cancer-associated myofibroblasts.

\section{Acknowledgements}

The present study was funded by the National Natural Science Foundation of China (grant nos. 30672104 and 30900549) and the Scientists Fund of Shandong Province (grant no. 2007BS03060).

\section{References}

1. Wang XC, Katso R, Butler R, Hanby AM, Poulsom R, Jones T, Sheer D and Ganesan TS: H-RYK, an unusual receptor kinase: Isolation and analysis of expression in ovarian cancer. Mol Med 2: 189-203, 1996.

2. Polanska UM and Orimo A: Carcinoma-associated fibroblasts: Non-neoplastic tumour-promoting mesenchymal cells. J Cell Physiol 228: 1651-1657, 2013. 
3. Fonseca FP, Coletta RD, Azevedo MB, Prado RAC, Pires SAM, Miyahara GI, Carlos R, Farthing P, Hunter KD, Speight PM, et al: Stromal myofibroblasts in squamous cell carcinoma of the tongue in young patients - a multicenter collaborative study. Oral Surg Oral Med Oral Pathol Oral Radiol 118: 483-489, 2014.

4. Mao Y, Keller ET, Garfield DH, Shen K and Wang J: Stromal cells in tumor microenvironment and breast cancer. Cancer Metastasis Rev 32: 303-315, 2013.

5. Hanahan D and Weinberg RA: Hallmarks of cancer: The next generation. Cell 144: 646-674, 2011.

6. Jezierska-Drutel A, Rosenzweig SA and Neumann CA: Role of oxidative stress and the microenvironment in breast cancer development and progression. Adv Cancer Res 119: 107-125, 2013.

7. Bianchetti L, Barczyk M, Cardoso J, Schmidt M, Bellini A and Mattoli S: Extracellular matrix remodelling properties of human fibrocytes. J Cell Mol Med 16: 483-495, 2012.

8. Göritz C, Dias DO, Tomilin N, Barbacid M, Shupliakov O and Frisén J: A pericyte origin of spinal cord scar tissue. Science 333 238-242, 2011

9. Coen M, Gabbiani $G$ and Bochaton-Piallat ML: Myofibroblast-mediated adventitial remodeling: An underestimated player in arterial pathology. Arterioscler Thromb Vasc Biol 31: 2391-2396, 2011.

10. Direkze NC, Hodivala-Dilke K, Jeffery R, Hunt T, Poulsom R, Oukrif D, Alison MR and Wright NA: Bone marrow contribution to tumor-associated myofibroblasts and fibroblasts. Cancer Res 64: 8492-8495, 2004

11. Mishra PJ, Mishra PJ, Glod JW and Banerjee D: Mesenchymal stem cells: Flip side of the coin. Cancer Res 69: 1255-1258, 2009.

12. Tschumperlin DJ, Liu F and Tager AM: Biomechanical regulation of mesenchymal cell function. Curr Opin Rheumatol 25: 92-100, 2013.

13. Prockop DJ: Marrow stromal cells as stem cells for nonhematopoietic tissues. Science 276: 71-74, 1997.

14. Dominici M, Le Blanc K, Mueller I, Slaper-Cortenbach I, Marini F, Krause D, Deans R, Keating A, Prockop Dj and Horwitz E: Minimal criteria for defining multipotent mesenchymal stromal cells. The International Society for Cellular Therapy position statement. Cytotherapy 8: 315-317, 2006

15. Zhao HF, Chen J, Xu ZS and Zhang KQ: Distribution and differentiation of mesenchymal stem cells in tumor tissue. Chin Med J (Engl) 122: 712-715, 2009.

16. Zhang K, Shi B, Chen J, Zhang D, Zhu Y,Zhou C, Zhao H, Jiang X and $\mathrm{Xu} \mathrm{Z}$ : Bone marrow mesenchymal stem cells induce angiogenesis and promote bladder cancer growth in a rabbit model. Urol Int 84: 94-99, 2010.

17. Zoja C, Garcia PB, Rota C, Conti S, Gagliardini E, Corna D, Zanchi C, Bigini P, Benigni A, Remuzzi G and Morigi M: Mesenchymal stem cell therapy promotes renal repair by limiting glomerular podocyte and progenitor cell dysfunction in adriamycin-induced nephropathy. Am J Physiol Renal Physiol 303 F1370-F1381, 2012.

18. Brennen WN, Denmeade SR and Isaacs JT: Mesenchymal stem cells as a vector for the inflammatory prostate microenvironment. Endocr Relat Cancer 20: R269-R290, 2013.

19. Rous P, Kidd JG and Smith WE: Experiments on the cause of the rabbit carcinomas derived from virus-induced papillomas. II. Loss by the $\mathrm{Vx} 2$ carcinoma of the power to immunize hosts against the papilloma virus. J Exp Med 96: 159-174, 1952

20. Gabbiani G and Majno G: Dupuytren's contracture: Fibroblast contraction? An ultrastructural study. Am J Pathol 66: 131-146, 1972 .

21. Angadi PV, Kale AD and Hallikerimath S: Evaluation of myofibroblasts in oral submucous fibrosis: correlation with disease severity. J Oral Pathol Med 40: 208-213, 2011.

22. Gupta K, Metgud R and Gupta J: Evaluation of stromal myofibroblasts in oral leukoplakia, oral submucous fibrosis, and oral squamous cell carcinoma - an immunohistochemical study. J Cancer Res Ther 11: 893-898, 2015.

23. Schmitt-Gräff A, Desmoulière A and Gabbiani G: Heterogeneity of myofibroblast phenotypic features: An example of fibroblastic cell plasticity. Virchows Arch 425: 3-24, 1994.
24. Saw VP, Schmidt E, Offiah I, Galatowicz G, Zillikens D, Dart JK, Calder VL and Daniels JT: Profibrotic phenotype of conjunctival fibroblasts from mucous membrane pemphigoid. Am J Pathol 178: 187-197, 2011.

25. Mayrand D, Laforce-Lavoie A, Larochelle S, Langlois A, Genest H, Roy M and Moulin VJ: Angiogenic properties of myofibroblasts isolated from normal human skin wounds. Angiogenesis 15: 199-212, 2012.

26. Lúcio PS, Cavalcanti AL, Alves PM, Godoy GP and Nonaka $\mathrm{CF}$ : Myofibroblasts and their relationship with oral squamous cell carcinoma. Braz J Otorhinolaryngol 79: 112-118, 2013 (In Portuguese).

27. Mertens JC, Fingas CD, Christensen JD, Smoot RL, Bronk SF, Werneburg NW, Gustafson MP, Dietz AB, Roberts LR, Sirica AE and Gores GJ: Therapeutic effects of deleting cancer-associated fibroblasts in cholangiocarcinoma. Cancer Res 73: 897-907, 2013.

28. Li H, Fan X and Houghton J: Tumor microenvironment: The role of the tumor stroma in cancer. J Cell Biochem 101: 805-815, 2007.

29. Wang J, Ying G, Wang J, Jung Y, Lu J, Zhu J, Pienta KJ and Taichman RS: Characterization of phosphoglycerate kinase-1 expression of stromal cells derived from tumor microenvironment in prostate cancer progression. Cancer Res 70 471-480, 2010.

30. Hu M, Peluffo G, Chen H, Gelman R, Schnitt S and Polyak K: Role of COX-2 in epithelial-stromal cell interactions and progression of ductal carcinoma in situ of the breast. Proc Natl Acad Sci USA 106: 3372-3377, 2009

31. Ostman A and Augsten M: Cancer-associated fibroblasts and tumor growth - bystanders turning into key players. Curr Opin Genet Dev 19: 67-73, 2009.

32. Tuxhorn JA, Ayala GE, Smith MJ, Smith VC, Dang TD and Rowley DR: Reactive stroma in human prostate cancer: Induction of myofibroblast phenotype and extracellular matrix remodeling. Clin Cancer Res 8: 2912-2923, 2002.

33. Lewis MP, Lygoe KA, Nystrom ML, Anderson WP, Speight PM, Marshall JF and Thomas GJ: Tumor-derived TGF- $\beta 1$ modulates myofibroblast differentiation and promotes HGF/SF-dependent invasion of squamous carcinoma cells. Br J Cancer 90: 822-832, 2004.

34. Ishii G, Sangai T, Oda T, Aoyagi Y, Hasebe T, Kanomata N, Endoh Y, Okumura C, Okuhara Y, Magae J, et al: Bone-marrow-derived myofibroblasts contribute to the cancer-induced stromal reaction. Biochem Biophys Res Commun 309: 232-240, 2003.

35. Kalluri R and Neilson EG: Epithelial-mesenchymal transition and its implications for fibrosis. J Clin Invest 112: 1776-1784, 2003.

36. Mishra PJ, Mishra PJ, Humeniuk R, Medina DJ, Alexe G, Mesirov JP, Ganesan S, Glod JW and Banerjee D: Carcinoma-associated fibroblast-like differentiation of human mesenchymal stem cells. Cancer Res 68: 4331-4339, 2008

37. Oktem G, Sercan O, Guven U, Uslu R, Uysal A, Goksel G, Ayla S and Bilir A: Cancer stem cell differentiation: TGF $\beta 1$ and versican may trigger molecules for the organization of tumor spheroids. Oncol Rep 32: 641-649, 2014.

38. Jeon ES, Moon HJ, Lee MJ, Song HY, Kim YM, Cho M, Suh DS Yoon MS, Chang CL, Jung JS and Kim JH: Cancer-derived lysophosphatidic acid stimulates differentiation of human mesenchymal stem cells to myofibroblast-like cells. Stem Cells 26: 789-797, 2008.

39. Ho IA, Yulyana Y, Sia KC, Newman JP, Guo CM, Hui KM and Lam PY: Matrix metalloproteinase-1-mediated mesenchymal stem cell tumor tropism is dependent on crosstalk with stromal derived growth factor $1 / \mathrm{C}-\mathrm{X}-\mathrm{C}$ chemokine receptor 4 axis. FASEB J 28: 4359-4368, 2014.

40. Berger L, Shamai Y, Skorecki KL and Tzukerman M: Tumor specific recruitment and reprogramming of mesenchymal stem cells in tumorigenesis. Stem Cells 34: 1011-1026, 2016. 